\title{
Female Artists and the Digitization of Labor in the Music Industry
}

\author{
Ian C. Strachan ${ }^{1}$ \\ ${ }^{1}$ College of Business, West Texas A\&M University, WTAMU Box 60268, Canyon, TX 79016-0001, USA \\ Correspondence: Ian C. Strachan, College of Business, West Texas A\&M University, WTAMU Box 60268, Canyon, \\ TX 79016-0001, USA. Tel: 806-651-3865. E-mail: istrachan@wtamu.edu
}

Received: November 27, 2014

Accepted: December 10, 2014

Online Published: December 11, 2014

doi:10.5430/bmr.v3n4p51

URL: http://dx.doi.org/10.5430/bmr.v3n4p51

\begin{abstract}
The digital revolution brought about by new technology and the eroding of intellectual property rights has simultaneously brought about increased opportunity as well as increased competition among content creators in the music industry - artists and bands as well as record labels. This change is evident in the "long tail" and "superstar effects" hollowing out the middle class of artists as well as lowering barriers to entry. It is well documented that women are still under-represented in many fields of the modern economy. Given this background, how do female pop artists fare in the music industry over time? This research utilizes a sample of the Billboard Hot 100 charts from the 1990s and 2000s and finds that female artists are dramatically and consistently under-represented on the pop charts. Though the percentage of female solo artists is nearly $50 \%$, female artists still account for less than a quarter of the total artists who make the charts. At the same time female solo artists and groups with at least one female artist are remarkably more productive at producing pop hits than male solo artists and groups with no female artist involvement. This, perhaps, represents an opportunity for entrepreneurial female artists in the future as production and consumption bottlenecks are dismantled in a superstar-dominated culture.
\end{abstract}

Keywords: Entrepreneurship, Gender diversity, Economics of the arts

\section{Introduction}

Major restructuring in creative industries has been brought about by the advent of digital technologies over the last twenty years. In the recorded music industry in particular restructuring has emerged from the use of MP3s and large-scale file sharing over networks, which has eroded intellectual property rights, diminished royalty revenue streams, and squeezed incomes for content creators. Generally this would appear to be the double-edged sword of Schumpeterian creative destruction: old business models become obsolete and new ways of doing things emerge to take their place (Schumpeter, 1942). Some in this industry are hurt while others, who are perhaps more adept along with insurgent entrepreneurs - likely benefit. In light of these technological changes many questions have been addressed by researchers, but the main theme has centered around inquiring: who are the winners and who are the losers as methods of utilizing new technology mature? This maturation occurs up and down the supply chain and at the level of the end user/consumer. Which artists, bands, record labels, copyright collectives, and digital retail platforms are leveraging the new technology to their advantage? (e.g. Brynjolfsson, Hu, \& Simester, 2011; Brynjolfsson, Hu, \& Smith, 2003; Brynjolfsson, Hu, \& Smith, 2006). The popular recorded music industry has had many bottlenecks on the supply-side due to the presence of concentrated record companies often acting as gatekeepers in the positive sense and the negative sense (Tschmuck, 2006). More specifically, there has existed a scarcity of resources available for investment in new talent, a scarcity of physical shelf space and limited marketing channels. Furthermore, consumers of recorded music were limited by technology in the analog world. The music industry has been and still is a concentrated superstar market (Rosen, 1981; Frank \& Cook, 1995; Giles, 2006). But in the new digital economic reality scarcity has disappeared and it is potentially much easier for new entrants to get a foothold and for consumers of popular culture to quickly gain access to content they are interested in (Anderson 2006, Page \& Garland, 2009). This would suggest the potential for entrepreneurial artists and innovative business models to benefit from the restructuring. Some recent research has found that there is a simultaneous 'superstar effect' with more concentration, and a 'long tail effect' with more diversity (Elberse \& Oberholzer-Gee, 2008; Strachan, 2010). This would imply a more homogenous industry enhancing what is already popular, and paradoxically even more competition and abundance at the lower end. Digital technology brings about this contradiction; it is a double-edged sword for business and culture. 
However, the present study is interested in the plight of female artists in the popular music industry. If there is potentially enhanced opportunity for new entrants, a leveling of the playing field, a democratization of culture via new digital technology and more 'open' marketing channels, female artists may be making inroads in pop music. It is well-documented that women are still under-represented in important areas of the modern economy such as Silicon Valley (Fenwick, 2013; Hu, 2013). Women are still paid less for equal work and equal qualifications (IWPR, 2010; ILO, 2013). Women earn less than men even when they set their own pay (Jacobs, 2014). Has disruptive digital technology effected the representation of women in the pop music industry? Has the new accessibility helped innovative female artists rise to the top?

Various studies find female artists significantly under-represented in pop culture markets. For example, the Arts Council of Finland found the average income of female artists to be lower than male artists, and this exists in the absence of any gender bias (Heikkinen \& Karhunen, 1996). Being a female artist poses a significant disadvantage for album sales, and this pattern persists in spite of the digital revolution (Fox \& Kochanowski, 2007). However, several studies show that female artists have relative success in the pop music industry. Bhattacharjee, Gopal, Lertwachara, Marsden, \& Telang (2007) find that albums featuring female artists have a distinct survival advantage on the charts compared with those that do not. This is corroborated by Giles (2007) for "number one hits". In a study focusing on the book industry, Verboord (2011) finds that female authors receive substantially more reviews online than in print media. This would lead one to surmise, at least, that there is potential for parity between male and female artists if only after a substantial institutional adjustment process.

As introduced above, digitization has brought about two paradoxical trends in popularity as measured by, for example, sales distributions. One is a leveling, democratizing force and a lowering of barriers to entry that would suggest increased opportunity for entrepreneurs. This potential for increased supply and variety has been termed the 'long tail' effect (Anderson, 2006; Page \& Garland, 2009). The other trend is a further concentration of sales among the ubiquitous few pop stars in a field which is already a classic case of a superstar or winner-take-all market. This potential for enhanced market share accruing to what is already popular has been termed the 'superstar' effect (e.g. Rosen, 1981; Adler, 2006). This superstar phenomenon in popularity distributions can emerge regardless of the distribution in talent (Adler, 1985; Chung \& Cox, 1994). Some studies find that both effects are operating simultaneously while the middle class is shrinking. Intuitively, this mirrors trends in the broader macroeconomy in terms of wealth and income distribution. This simultaneous effect holds true for many cultural fields affected by digitization such as the movie industry (Elberse \& Oberholzer-Gee, 2008). Digital marketing channels have allowed supply and variety to expand, consumers have more choice, (e.g. Brynjolfsson et al., 2006) there are less barriers to entry and lower production and marketing costs on the supply-side. The cost of recording music has fallen. For example, consider the decentralized efficiency gain from computer programs such as Apple's Garage Band. (Note 1) If production and consumption bottlenecks are loosened, consumers can connect more easily and cheaply with content they desire, and culture can be re-invigorated with boundless shelf space expanding variety and potentially infinite possibilities for innovative creative expression by entrepreneurs if they find their fans and monetize their value proposition.

At least the latter description is the potential in this industry (e.g. Gomes, 2006). Considering the popular music industry, then, one would suppose that the representation of female artists would more likely mirror the gender percentages representative of the population at large in the United States. Surely with the Internet at our fingertips, nearly instantaneously gratifying our consumption desires, gender discrimination and gender bias within cultural and artistic fields should be a thing of the past or at least diminishing relative to previous decades? The structure of this research proceeds as follows: In section II, the motivation for this research is outlined in more detail drawing from more specific trends in the literature; Section III describes the data utilized here and an analysis of the findings; Section IV provides conclusions, discussion, and some implications for the future.

\section{Motivation: “It's a Man's Man's Man's World" (Note 2)}

Does gender matter for success in pop music? Are men more successful than women? In many important sectors of the economy women are not achieving the same status as men. This has certainly been true historically and remains stubbornly so in modern times. (e.g. IWPR, 2010) Referring to Table 1 below, women typically make up about $25 \%$ of the Billboard Hot 100 charts. (Note 3) This broad under-representation can be viewed as a threat and an opportunity given that the pop music industry is, in theory, restructuring due to technology change. For example, if female artists overtly or covertly experience discrimination through mainstream marketing channels, this is a bias that ought to come to light, just as it has in other industries such information technology (Fenwick, 2013; Hu, 2013) so business decisions can be better informed in these areas. Aside from maternal responsibilities, female artists - 
and potential female artists - may face discrimination and upbringings which are deleterious to artistic development (Cowen, 1996). (Note 4) Are there expectations placed upon females at a young age as they are first being exposed to art and music that consciously or unconsciously discourage them? This is likely to have occurred in the STEM sector (Huhman, 2012). And there is certainly support for this under-investment in the artistic sector leading to the under-representation of women (Cameron, 2003). It would be perhaps surprising if any gender bias among popular music fans - on the demand side of the market - refused to change over the years. How patriarchal can pop culture be? These questions cannot be answered here, nor can we confirm the causations suggested, but they serve to motivate the research question: has the digital revolution brought about a more equitable representation of female artists?

Other studies have addressed a similar agenda but not with respect to the popular music industry in the United States. This is important because the music industry (and content creation in general) in the U.S. has historically had and continues to have an outsized influence on popular culture the world over. Gender inequality has been a research topic of much interest, however the discussion on gender representation in the pop music industry is only very recently (at the time of time of this writing) coming to the fore. Those discussions which are occurring are largely speculative and anecdotal accounts in the media - a sample of which is outlined below. The data used in the present study is described below, but it is worth noting at this point that the project utilizes a novel data set tabulated with variables such as gender and the number of artists involved in each type of musical project. This component of the industry has not been examined in this way before.

Table 1. Gender representation on the ranks of the Hot 100 for 1965, 1975, 1985, 1995, and 2005.

\begin{tabular}{l|rrrrr} 
& 1965 & 1975 & 1985 & 1995 & 2005 \\
\hline \# Solo artists & 199 & 192 & 116 & 138 & 181 \\
\# Solo female artists & 53 & 51 & 32 & 55 & 52 \\
\% Female solo artists & $26.63 \%$ & $26.56 \%$ & $27.59 \%$ & $39.86 \%$ & $28.73 \%$ \\
\hline \# Groups & 146 & 169 & 118 & 148 & 82 \\
Total \# Women in groups & 80 & 69 & 57 & 84 & 20 \\
\hline Total \# Artists (solo and in groups) & 811 & 988 & 636 & 681 & 490 \\
Total \# Female artists (solo and in groups) & 133 & 120 & 89 & 139 & 72 \\
\% Female artists (solo and in groups) & $22.93 \%$ & $17.31 \%$ & $19.03 \%$ & $28.49 \%$ & $25.31 \%$ \\
\hline \# Songs by female solo artists & 103 & 74 & 57 & 79 & 84 \\
\% Songs by female solo artists & $24.58 \%$ & $26.15 \%$ & $27.67 \%$ & $44.38 \%$ & $27.36 \%$ \\
Source: Whitburn(2012 \& 2011). & & & & & \\
\hline
\end{tabular}

There is an illusion - which seems to be backed up by many anecdotes in the media - that gender bias against women and the under-representation of women is a thing of the past. Women are being empowered - this is generally a narrative in the music industry and in other areas of the economy. Industry observers consistently trumpet superstar women when they rise to the top of the charts (e.g. Newman, 2014; Kayim, 2011; and Lisi, 2014). However, the longer-term trends may be just the opposite. Observers may desire that skewed gender representation balances out. Things may seem anecdotally better, folks want the distribution of success to improve but is there evidence for that in the data? It may be that fans and musicians expect that women are making inroads - i.e. achieving comparable success to men - because of the ubiquitous nature of multi-media superstars due to digital technology and perhaps strong marketing/promotion efforts.

On the other hand, there are serious accusations of sexism and exploitation of women in the pop music industry (e.g. Smith 2013; and Woszczyna, 2013). There is a narrative that presumes that females have the advantage right now while at the same time deriding objectification and sexualization of marketing strategies that get them there (Gill, 2013). It is not obvious what precisely it means when someone says: "the music industry discriminates against women". Superficially, the popularity game would seem to be won by talent. So if women are under-represented, 
does that mean the "movers and shakers" of the industry "old boy network" are shutting out women? Or does that mean that fans prefer male artists? Or are women not encouraged at a young age to learn how to play a guitar and play in a rock 'n' roll band? This could be more broadly considered: sexism. Again, these specific questions are outside of the scope of this research paper. Furthermore, it is worth noting that women are still vastly under-represented in the ranks of global billionaires across all industries. However: "This trend is unlikely to reflect a lack of creativity among women, as women tend to perform better in the sectors where superstars and globalization (the so-called winner-take-all industries, such as high-tech and consumer goods) are more important. These industries account for 43 percent of female self-made billionaires in 2014, compared with 33 percent of male self-made billionaires." (Freund \& Oliver, 2014). So this would portend a positive outlook for female artists in pop music. Which, if any, of these observations are backed up by actual data?

\section{Data and Analysis}

This research utilizes a sample of the top 50 of the Hot 100 singles charts in the United States from five years: 2011 (the most recent year available at the time of writing), 2006, 2001, 1996 and 1991. The top 50, then, is the top half of the pop charts - i.e. the most popular half of the most popular singles. These data are sourced from Pop Annual 1955-2011, 8th edition by Joel Whitburn (Whitburn, 2012). Singles have far fewer tracks than albums, perhaps only one or two. Songs available on singles serve a promotional purpose and come out later on albums (Phillips \& Strachan, 2014). The Whitburn book has chart data compiled from Billboard's Top Pop Singles Charts from the years 1955-2011. Each single has a "product life cycle", rising up the rankings after release, peaking, and then falling back down the rankings quickly or slowly depending on staying power or "survival". Therefore we can observe all the singles that peaked on Billboard's main pop singles charts at each of the 100 rankings. Multiple songs - or, in a sprinkling of cases, zero songs - may peak at each of the 100 positions in any particular year. (Note 5) This means that there are well over 100 songs and more than 100 artists and bands represented on the Hot 100 . The rankings are based on radio airplay and point of sale information from music retail stores. The exact method of calculation of these rankings has been revised several times over the years. Playlists from radio stations, surveys of retail sales outlets, monitored radio airplay, point of sale information, and, more recently, digital downloads have all been part of the calculation. The electronic sales information collected by Nielsen Soundscan is used by most music industry operators and has been used to create the Billboard music charts since 1991 (Phillips \& Strachan, 2014, page 22).

We observe three different productive units on the Hot 100. In the rational, economic sense a productive unit means creative inputs coming together to produce recorded music output. These are: 1) solo artists, 2) groups, and 3) collaborations. A solo artist is a single artist with a unique listing. (Note 6) "Groups" are a productive unit with two or more members - again, uniquely listed. (Note 7) "Collaborations" are the same as a group in terms of having two or more members but they are temporary and have no unique listing in Whitburn's text (Whitburn, 2011). Therefore a collaboration could be separate solo artists coming together for a project, one or more solo artists temporarily joining with a group, or in some cases two groups joining forces temporarily. So in many cases, then, collaborations are short-lived side projects and utilize "guest" singers and/or rappers.

Table 2 displays the total number of songs making the top 50 of the Hot 100 which fall under each category of productive unit: songs by solo artists, groups, and collaborations. (Note 8) Secondly, the percentages of those songs credited to female solo artists, the percentage of songs by groups with at least one female, and the percentage of songs by collaborations with at least one female are shown. (Note 9)

Table 2 . Number of songs making the top 50 by gender.

\begin{tabular}{lrrrrr}
\hline & 1991 & 1996 & 2001 & 2006 & 2011 \\
\hline Total songs & 245 & 213 & 193 & 187 & 196 \\
\hline$\%$ at least one female & $35.51 \%$ & $40.85 \%$ & $40.93 \%$ & $39.04 \%$ & $43.88 \%$ \\
\hline Songs by solo artists & 110 & 76 & 106 & 86 & 84 \\
\hline$\%$ songs by female & $49.09 \%$ & $57.89 \%$ & $48.11 \%$ & $38.37 \%$ & $50.00 \%$ \\
\hline Songs by groups & 119 & 110 & 58 & 42 & 29 \\
\hline$\%$ at least one female & $19.33 \%$ & $26.36 \%$ & $20.69 \%$ & $26.19 \%$ & $34.48 \%$ \\
\hline Songs by collaborations & 16 & 27 & 29 & 59 & 83 \\
\hline$\%$ at least one female & $62.50 \%$ & $51.85 \%$ & $55.17 \%$ & $49.15 \%$ & $40.96 \%$ \\
\hline
\end{tabular}

Source: compiled from Whitburn (2012) and author's own calculations 
It could be surmised in Table 2 that with the slightly declining number of total songs year-to-year, there may be a downward trend in variety in the pop charts. (Note 10) The number of songs where one or more female artist is involved remains in the $30-40 \%$ range. 2011 is the highest with nearly $44 \%$ while 1991 is the lowest with $35 \%$. Therefore men are consistently in the majority to the tune of $60 \%$ of the songs on the charts with zero female artists credited. (Note 11) About half of the total songs in this sample are by solo artists and close to half of those are by female solo artists. This remains fairly stable over this sample. The percent in this sample by groups with at least one female involved ranges between $20 \%$ and $30 \%$ with no clear pattern. In what may be a broader trend, the number of songs by collaborations are becoming more common while songs by groups are less common. However, songs by collaborations with at least one female involved actually declines over the 5 years sampled from $62 \%$ in 1991 to $40 \%$ by 2011. This is clear evidence that men dominate the makeup of collaborations and groups - before and after the digital revolution.

Table 3 shows the female artist representation among the unique productive units: solo, groups, and collaborations (Note 12) - i.e. the number and percentage of female artists. The number of songs declines slightly each year and so does the number of unique solo artists, groups and collaborations. Once again, this may imply less variety in the pop music charts. Of all of the artists tabulated from groups, collaborations and solo acts, the percentage of female artists remains under $25 \%$. The lowest is $15 \%$ in 1991, up to $25 \%$ in 2011 , and this returns to below $18 \%$ in 2011 .

Table 3. Female artist representation among unique productive units.

\begin{tabular}{lrrrrr}
\hline & 1991 & 1996 & 2001 & 2006 & 2011 \\
\hline $\begin{array}{l}\text { Unique solo } \\
\text { artists, groups \& } \\
\text { collaborations }\end{array}$ & 179 & 170 & 160 & 162 & 155 \\
\hline $\begin{array}{l}\text { Number of } \\
\text { female artists }\end{array}$ & 75 & 94 & 91 & 91 & 65 \\
\hline $\begin{array}{l}\text { Percent female } \\
\text { artists }\end{array}$ & $15.46 \%$ & $19.79 \%$ & $25.07 \%$ & $24.86 \%$ & $17.81 \%$ \\
\hline
\end{tabular}

Source: compiled from Whitburn (2012) and author's own calculations.

Table 4. Female artist representation among solo acts, collaborations and groups.

\begin{tabular}{lrrrrr}
\hline & 1991 & 1996 & 2001 & 2006 & 2011 \\
\hline Solo artists & 80 & 61 & 84 & 69 & 52 \\
\hline \% female & $42.50 \%$ & $57.38 \%$ & $47.62 \%$ & $39.13 \%$ & $42.31 \%$ \\
\hline $\begin{array}{l}\text { Collaboratio } \\
\text { ns }\end{array}$ & 14 & 27 & 28 & 59 & 82 \\
\hline $\begin{array}{l}\text { Artists in } \\
\text { collaboratio }\end{array}$ & 48 & 94 & 84 & 157 & 227 \\
ns & & & & & \\
\hline $\begin{array}{l}\text { \% female } \\
\text { Groups }\end{array}$ & $18.75 \%$ & $30.85 \%$ & $25.00 \%$ & $26.11 \%$ & $16.74 \%$ \\
\hline $\begin{array}{l}\text { Artists in } \\
\text { groups }\end{array}$ & 85 & 82 & 48 & 34 & 21 \\
\hline$\%$ female & $8.96 \%$ & 320 & 195 & 140 & 86 \\
\hline
\end{tabular}

Source: compiled from Whitburn (2012) and author's own calculations. 
Table 4 displays female artist representation among the three productive units: solo artists, collaborations, and groups. More artists are involved in collaborations and fewer artists are involved in groups over time. This trend is very pronounced and seems to be consistent. The number of artists in collaborations rises from 48 in 1991 to 227 by 2011 . The number of artists in groups falls from 357 in 1991 to 86 in 2011. Around half of the solo artists are female among those peaking on the top 50 slots of the Hot 100. However, female artists are quite substantially under-represented in collaborations, ranging from a high of $31 \%$ in 1996 to a low of $17 \%$ in 2011 , the latest year available. There is even more scarcity of female artists in groups; this percent ranges from $9 \%$ in 1991, to a high of just over 16\% in 2006 to back below 6\% in 2011. These trends from Table 4 are pictured more clearly in Figure 1 below for each of the five years.

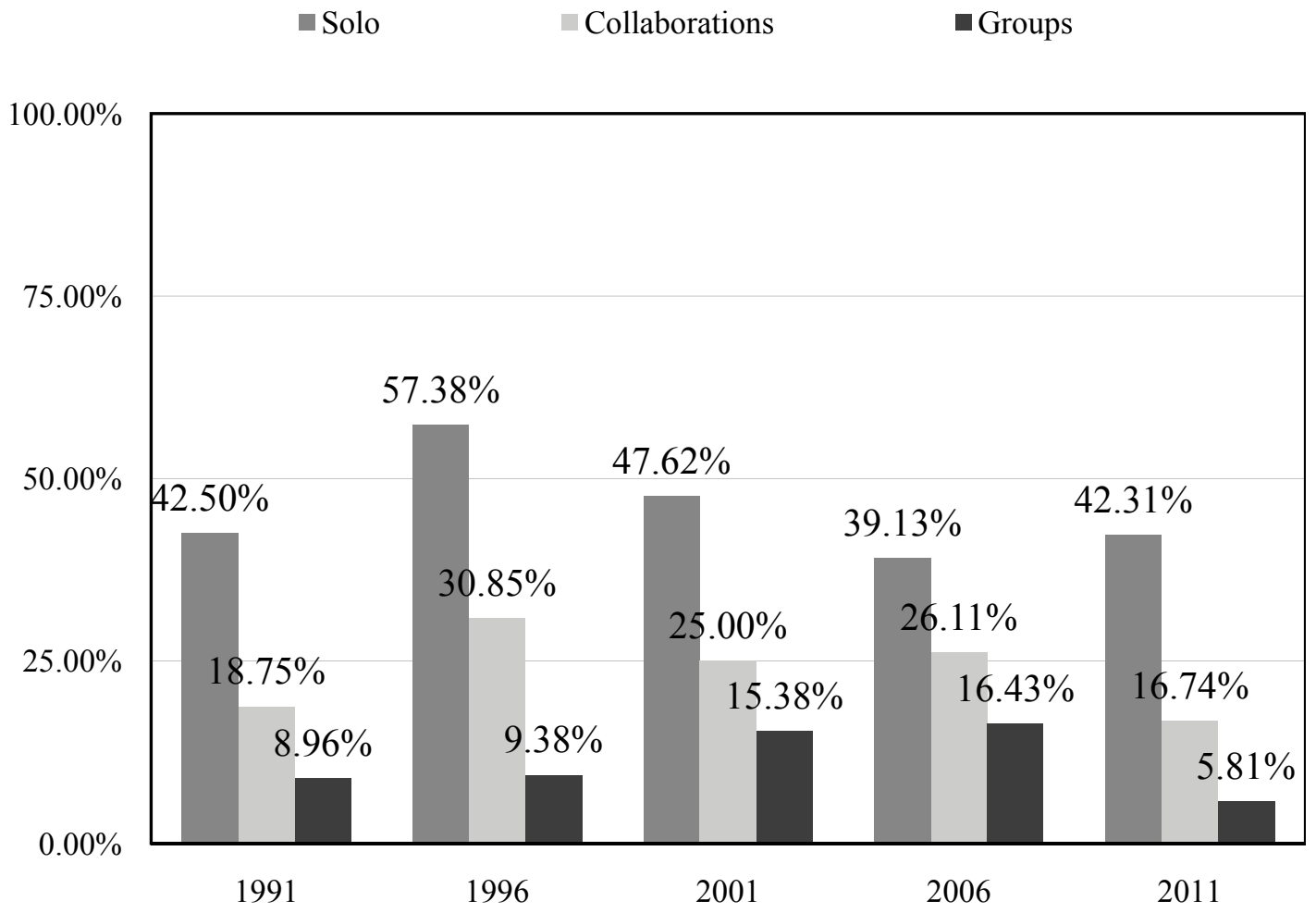

Figure 1. Female artist representation among solo acts, collaborations and groups in the top 50 for 1991, 1996, 2001, 2006, and 2011. Source: compiled from Whitburn (2012) and author's own calculations.

Do women compensate for this under-representation by being productive individually? Referring to Table 5, yes, they do. There is likely something historically/culturally unique about women as artists; in this cultural milieu they are likely more specialized as singers and therefore may have a proclivity to break off on their own and go solo. (Note 13) Table 5 shows average productivity in each year, that is, the average number of charting singles per productive unit: solo artists, groups and collaborations. Female solo artists chart more singles than male solo artists on average in four out of the five years. 2011 exhibits the largest difference in productivity between male and female solo artists: 1.91 songs per female versus 1.40 songs per male artist. This may be evidence that women artists are making inroads more recently, adding support to that narrative in the media. Groups seem to indicate a similar trend. Groups with at least one female artist chart more singles than groups with no female artist in three out of the 5 years with 2001 being essentially a toss-up. And again, 2011 is the year with the largest difference in average productivity: 2 songs per group for the groups with at least one female and 1.25 songs per group for those groups devoid of females. Due to the nature of collaborations as temporary groupings or side projects featuring solo artists and artists from other bands, they generally average out at one song per year. Collaborations typically do not release more than one single in a year compared to groups which do release more. Therefore, aside from the under-representation of females in collaborations by artists and songs shown above, there is little difference in collaborations' average productivity between those with and without female artists in four out of the five years sampled here. 
Table 5. Average song productivity by gender in the top 50 of the Hot 100 .

\begin{tabular}{lccccc}
\hline & 1991 & 1996 & 2001 & 2006 & 2011 \\
\hline $\begin{array}{l}\text { + Female } \\
\text { solo artists }\end{array}$ & 1.59 & 1.26 & 1.28 & 1.22 & 1.91 \\
\hline $\begin{array}{l}\text { T Male solo } \\
\text { artists }\end{array}$ & 1.22 & 1.23 & 1.23 & 1.26 & 1.40 \\
\hline $\begin{array}{l}\text { Groups with } \\
\text { at least one }\end{array}$ & 1.44 & 1.61 & 1.20 & 1.00 & 2.00 \\
female & 1.39 & 1.27 & 1.21 & 1.35 & 1.25 \\
\hline $\begin{array}{l}\text { Groups with } \\
\text { no female }\end{array}$ & 1.00 & 1.00 & 1.00 & 1.00 & 1.00 \\
\hline $\begin{array}{l}\text { Collaboratio } \\
\text { ns with at } \\
\text { least } \text { one } \\
\text { female }\end{array}$ & 1.20 & 1.00 & 1.00 & 1.00 & 1.00 \\
\hline $\begin{array}{l}\text { Collaboratio } \\
\text { ns with no } \\
\text { female }\end{array}$ & & & & & \\
\hline
\end{tabular}

Source: compiled from Whitburn 2012 and author's own calculations.

\section{Conclusions}

The digital revolution, circa 2000, has simultaneously brought about increased opportunity and competition among content creators. The playing field has been leveled, barriers to entry have been removed, and entrepreneurial new artists potentially can find a foothold in ways they could not in previous decades. Old business models have been undermined, supply bottlenecks have been opened, and music fans can access content they are looking for more quickly and easily. We are interested in how female artists have done, given this potentiality. Of the portions of the Hot 100 charts sampled here, women are under-represented on the charts in general. This observation persists over the decades. Tabulating female artists out of all of the artists making the top 50 rankings of the Hot 100, female artists typically account for less than a quarter of the total artists who make the charts. In particular, women are very scarce as members of both groups and collaborations. On the other hand, females make up right around half of the solo artists making the charts. On average, female solo artists are more productive than male solo artists in four out of five of the years analyzed.

Empirically, this study's limitations are derived from the data source being truncated as it is - by only the top half of the Hot 100. There are likely some differences in the variety of artists/groups making the charts at rankings below a rank of 50 that are not captured here. There is undoubtedly a sizable culture of independent artists and fans who, by their own ethos, eschew popularity and are not observed here. Furthermore, the most recent year with available complete data at the time of writing is 2011. It may be the case that some institutional changes occur relatively quickly and exponentially. The limited data analysis presented here cannot draw conclusions about why women are so scarce on the pop charts over the years. But it can provide context for the debate. Future research can inquire into more complex relationships between female artists and groups. For example, are female solo artists more likely to quit their original band? Why are there so few female artists in bands to begin with? Are female artists more likely to join side projects and collaborations than male artists?

In a rote economic sense, these popularity rankings on the charts are the result of supply and demand interaction, whether or not it is a 'free' market with relative competitiveness - sufficient new entrants — or not. Certainly there is competition among artists and groups. But it's just as true that there still are bottlenecks, intermediaries and massive oligopoly power on the supply side. The industry shapes demand through various forms of market power and marketing techniques. Music consumers' attention spans are still limited, even with all of the time-shifting and space-shifting occurring with the new digital platforms. But the pop music industry must respond to some extent to already existing demand and consumer preferences. There are many moving parts here. Simply put: is this discrimination or self-selection? And assuming it is not discrimination, what is different about the role that women play as artists that makes them so effective as individuals but so scarce in groupings with other artists? 
All in all, these trends can be viewed as both a threat and an opportunity - both negatively and positively. Women are lacking in numbers in the pop music industry, but they are just as productive as men at turning out hit singles. Perhaps this can help to justify backing/investing in female artists and bands with some or all female members. Basically: women have been and still are vastly under-represented on the pop charts du jour, however, they are extraordinarily productive therefore they could and should make inroads in the future. This is, hopefully, an opportunity. The new economic landscape favors entrepreneurs who are able to innovate. Potential female entrepreneurs are often constrained by fear of failure on the one hand, and on the other encouraged by positive role models (Noguera, Alvarez, \& Urbano, 2013). With this in mind, perhaps the trends elucidated here can contribute to the dialogue surrounding female entrepreneurial capability in the future.

\section{References}

Adler, M. (1985). Stardom and Talent. American Economic Review. 75, 208-212.

Adler, M. (2006). Chapter 25 Stardom and Talent. Handbook of the Economics of Art and Culture, 895-906. $\mathrm{http}: / / \mathrm{dx}$.doi.org/10.1016/s1574-0676(06)01025-8

Anderson, C. (2006). The Long Tail: Why the Future of Business is Selling Less of More. New York: Hyperion.

Bhattacharjee, S., R.D. Gopal, K. Lertwachara, J.R. Marsden, \& R. Telang. (2007). The Effect of Digital Sharing Technologies on Music Markets: A Survival Analysis of Albums on Ranking Charts. Management Science. 53:9, 1359-1374. http://dx.doi.org/10.1287/mnsc. 1070.0699

Brynjolfsson, E., Y. Hu, \& D. Simester. (2011). Goodbye Pareto Principle, Hello Long Tail: The Effect of Search Costs on the Concentration of Product Sales. Management Science, 57(8) 1373-1386. http://dx.doi.org/10.1287/mnsc.1110.1371

Brynjolfsson, E., Y. Hu, \& M. Smith. (2003). Consumer Surplus in the Digital Economy: Estimating the Value of Increased Product Variety at Online Booksellers. Management Science. 49(11) 1580-1596. http://dx.doi.org/10.1287/mnsc.49.11.1580.20580

Brynjolfsson, E., Y. Hu, \& M. Smith. (2006). From Niches to Riches: Anatomy of the Long Tail. Sloan Management Review. 47(4) 67-71.

Cameron, S. (2003). The Political Economy of Gender Disparity in Musical Markets. Cambridge Journal of Economics, Vol. 27, Issue 6, 905-917. http://dx.doi.org/10.1093/cje/27.6.905

Chung, K.H. \& R.A.K. Cox. (1994). A Stochastic Model of Superstardom: An Application of the Yule Distribution. The Review of Economics and Statistics. 76(4) 771-775. http://dx.doi.org/10.2307/2109778

Cowen, T. (1996). Why Women Succeed, and Fail, in the Arts. Journal of Cultural Economics. 20, 93-113. http://dx.doi.org/10.1007/s10824-005-3113-8

Elberse, A. \& F. Oberholzer-Gee. (2008). Superstars and Underdogs: An Examination of the Long-Tail Phenomenon in Video Sales. Working Paper. July 1, 2008.

Fenwick. (2013). Gender Diversity in Silicon Valley. Mountain View: Fenwick \& West, LLP.

Fox, M.A. \& P. Kochanowski. (2007). Multi-Stage Markets in the Recording Industry. Popular Music and Society, Vol. 30, No. 2, 173-195. http://dx.doi.org/10.1080/03007760701267714

Frank, R.H. \& P.J. Cook. (1995). The Winner-Take-All Society: Why the Few at the Top Get So Much More Than the Rest of Us. New York: The Free Press.

Freund, C. \& S. Oliver. (2014). The Missing Women in the Inequality Discussion. Real Time Economics Issues Watch. Washington: Peterson Institute for International Economics.

Giles, D.E. (2006). Superstardom in the US Popular Music Industry Revisited. Economic Letters, 92: 68-74. http://dx.doi.org/10.1016/j.econlet.2006.01.022

Giles, D.E. (2007). Survival of the Hippest: Life at the Top of the Hot 100. Applied Economics, 39, 1877-1887. http://dx.doi.org/10.1080/00036840600707159

Gill, M. (2013, Aug. 27). Miley Cyrus, Lady Gaga, Rihanna - Pop Music is Dominated by Women Cashing in on their Sexuality. The Telegraph. Retrieved http://blogs.telegraph.co.uk/news/marthagill/100232706/miley-cyrus-lady-gaga-rhianna-pop-music-is-dominate d-by-women-cashing-in-on-their-sexuality/ 
Gomes, L. (2006, Aug. 2). Many Companies Still Cling to Big Hits to Drive Earnings. Wall Street Journal, Eastern Edition.

Heikkinen, M., \& P. Karhunen. (1996). Does Public Support Make a Difference, and for Whom? Journal of Cultural Economics. Volume 20, Issue 4, 341-358. http://dx.doi.org/10.1007/s10824-005-1358-x

Hu, E. (Reporter). (2013, Sept. 11). Sexism In The Tech Industry Takes Center Stage. All Things Considered. National Public Radio. $\quad$ Retrieved from http://www.npr.org/blogs/alltechconsidered/2013/09/11/221052414/sexism-in-the-tech-industry-takes-center-sta ge? $\mathrm{ft}=1 \& \mathrm{f}=1001$

Huhman, H. (2012, June 20). STEM Fields And The Gender Gap: Where Are The Women? Forbes: ForbesWomen. Retrieved from: http://www.forbes.com/sites/work-in-progress/2012/06/20/stem-fields-and-the-gender-gap-where-are-the-wome $\mathrm{n} /$

Institute for Women's Policy Research (IWPR). (2010). Separate and Not Equal? Gender Segregation in the Labor Market and the Gender Wage Gap. Washington: Institute for Women's Policy Research.

International Labour Organization (ILO). (2013). Equal Pay: An Introductory Guide. Geneva: International Labour Organization.

Jacobs, E. (2014). Women Earn Less Than Men Even When They Set the Pay. Financial Times. November 6, 2014.

Kayim, G. (2011, Aug. 3). Women Dominate Pop Music Industry. WeWomen.com: Women in Focus. Retrieved from: http://www.wewomen.com/career-finance/women-dominate-pop-music-industry-n158789.html

Lisi, J. (2014, Sept. 29). How Women Dominated Pop Music in the '00s. PopMatters. Retrieved from: http://www.popmatters.com/feature/185488-how-women-dominated-pop-music-in-the-00s/

Newman, M. (2014, Oct. 17). Female Artists Ruling the Charts: A Movement or Just a Moment? Billboard Magazine. Retrieved

from: http://www.billboard.com/articles/business/6288913/female-artists-chart-lorde-taylor-trainor-iggy-katy-nicki-ch arli-jessie-ariana-ora

Noguera, M., C. Alvarez, \& D. Urbano. (2013). Socio-cultural Factors and Female Entrepreneurship. International Entrepreneurship and Management Journal. 9(2). 183-197. http://dx.doi.org/10.1007/s11365-013-0251-x

Page, W. \& E. Garland. (2009). The Long Tail of P2P. PRS for Music. Issue 14, 1-8.

Phillips, R.J. \& I.C. Strachan. (2014). Breaking Up Is Hard To Do: The Resilience of the Rock Group as an Organizational Form for Creating Music. Journal of Cultural Economics. http://dx.doi.org/10.1007/s10824-014-9226-1

Rosen, S. (1981). The Economics of Superstars. The American Economic Review. 71(5). 845-858.

Schumpeter, J. A. (1942). Capitalism, Socialism, and Democracy. New York: Harper and Row Publishers.

Smith, C. (2013, Apr. 24). The Music Industry Discriminates Against Women, Chapter 10 Million — by Kate Nash. Radio.com. Retrieved from: http://news.radio.com/2013/04/24/kate-nash-music-women-discrimination/

Strachan, I.C. (2010). The Creative Destruction of the Winner-Take-All Society? Property Rights and the Economics of the Long Tail in the Music Industry. (Doctoral Dissertation). Colorado State University: Fort Collins.

Tschmuck, P. (2006). Creativity and Innovation in the Music Industry. The Netherlands: Springer.

Verboord, M.N.M. (2011). Cultural Products Go Online: Comparing the Internet and Print Media on Distributions of Gender, Genre and Commercial Success. Communications: the European Journal of Communication Research. 36(4), 441-462. http://dx.doi.org/10.1515/comm.2011.022

Whitburn, J. (2011). Top Pop Singles, 1955-2010 (13th ed.). Menomonee Falls, WI: Record Research.

Whitburn, J. (2012). Pop Annual, 1955-2011 (8th ed.). Menomonee Falls, WI: Record Research.

Woszczyna, N. (2013, Feb. 7). Sexism in the Music Industry Drives Female Pop Stars to Shocking Lows. Feminspire. Retrieved from: http://feminspire.com/sexism-in-the-music-industry-drives-female-pop-stars-to-shocking-lows/ 


\section{Notes}

Note 1. Presuming quality of music output is constant.

Note 2. This is the title of a song by James Brown.

Note 3. The data in Table 1 is sourced from Whitburn 2011 (see Phillips \& Strachan, 2014). It is a separate data set from the one utilized here.

Note 4. Cowen (1996) also hypothesizes on the one hand that female artistic accomplishments are not inferior to male artists, and on the other hand that women artists are, tongue-in-cheek, inferior for innate biological reasons. He finds some support for the former idea.

Note 5. For example, there was no song which peaked at the number 25 position in 2011 or at the number 27 position in 2006. Multiple songs "passed through" those ranks on their (discontinuous) journey up or down the charts.

Note 6. Uniquely mentioned in Top Pop Singles 1955-2010 13th edition by Joel Whitburn (Whitburn 2011). This second book has essentially the same time frame as the Pop Annual above and includes chart data compiled from Billboard's Pop Singles Charts from 1955 to 2010. This volume includes all hits that charted on Billboard's main pop singles charts from January 1, 1955, to January 8, 2011 (Phillips \& Strachan 2014, page 22).

Note 7. Regardless of whether or not the artists in the group are involved in side projects from time to time.

Note 8. Certain songs from ambiguous groups were dropped. E.g., from 1991, a song by The Simpsons (TV show), one song by The TAMI Show (a concert film), from 2006, six songs by "High School Musical cast", and from 2011, a total of 24 songs attributed to "Glee cast" were dropped.

Note 9. Gender identification was not found to be an issue in this particular sample. There are occasionally artists who change gender, such as the singer/guitarist from the band "Against Me!"

Note 10. Songs from TV shows were dropped.

Note 11. This does not include female songwriters, sound engineers, managers, consultants, etc.

Note 12. There is a small amount of double counting here of both male and female artists who are dually solo and/or in groups and/or in collaborations in the same year. Some examples are: from 1996: Keith Sweat w/ Athena Cage, Keith Sweat w/ KutKlose; from 2011: Jay-Z \& Kanye West, Jay-Z \& Kanye West w/ Otis Redding, Nicki Minaj, Nicki Minaj w/ Drake, and Nicki Minaj w/ Rihanna. For brevity’s sake these are not corrected for here.

Note 13. This is a question to be taken up in future research. 